\title{
Developing genetic counseling for male BRCA1/2 mutation carriers based on their own experiences
}

\author{
Outi Kajula ${ }^{* 1,2}$, Outi Kuismin ${ }^{2}$, Maria Kääriäinen ${ }^{1}$, Helvi Kyngäs ${ }^{1}$ \\ ${ }^{1}$ Research Unit of Nursing Science and Health Management, University of Oulu, Oulu, Finland \\ ${ }^{2}$ Department of Clinical Genetics, Oulu University Hospital, Oulu, Finland
}

Received: April 9, 2017

DOI: $10.5430 /$ jnep.v7n10p119
Accepted: May 21, 2017

Online Published: May 26, 2017

\begin{abstract}
Background: Previous studies of genetic counseling (GC) for male BRCA1/2 mutation carriers have focused on their level of satisfaction with the GC and its content. The aim of this study was to examine the GC experiences of male BRCA1/2 mutation carriers, and their suggestions for improving GC, more broadly.

Methods: Data were collected by themed interviews of Finnish male BRCA1/2 mutation carriers $(n=31)$, and subjected to inductive content analysis.

Results: The results indicated that the participants had a mixture of both positive and negative experiences of GC regarding operational conditions at Departments of Clinical Genetics (DCGs) and the ability of the counselors' (clinical geneticists or genetic nurses) to provide GC. Although the GC was implemented in a professional manner, according to the male participants, more concreate and illustrative information should be provided, and the counselors should receive additional training to provide such information and improve their communication skills.

Conclusions: Based on results of the study we make some suggestions for tailored GC for male BRCA1/2 mutation carriers. The results may facilitate development of a tentative model of GC that could be extended to broader categories of people at risk of hereditary cancer syndromes in the future.
\end{abstract}

Key Words: BRCA1, BRCA2, Male carriers, Genetic counseling, Experience, Development, Training

\section{INTRODUCTION}

Inherited pathogenic variants (hereafter mutations) of BRCA1 and BRCA2 (BRCA1/2) genes $^{[1,2]}$ increase risks of hereditary breast, ovarian and prostate cancer. For example, BRCA1 mutations reportedly confer a $8.6 \%$ cumulative risk of males developing prostate cancer by age 65 years $^{[3]}$ and $1.2 \%$ cumulative risk of developing breast cancer by age 70 years, ${ }^{[4]}$ while lifetime prostate cancer risks are reportedly $20 \%{ }^{[5]}$ and risks of breast cancer by age 80 years are $8.9 \%$ for male BRCA2 mutation carriers. ${ }^{[6]}$ Although cancer risk are lower for male BRCA1/2 mutation carriers than for female counterparts, male carriers are advised to self-examine their breasts and undergo yearly prostate specific antigen tests and digital rectal examinations from the age of $40 .^{[5,7]}$

The identification of BRCA1/2 provides the opportunity to offer genetic counseling (GC) and genetic testing to family members. Several recommendations have been made concerning the implementation of GC in clinical practices for people at risk of hereditary cancer syndromes. In GC sessions, genetic health-care professionals provide genetic knowledge and psychosocial support to counselees to help

\footnotetext{
* Correspondence: Outi Kajula; Email: outi.kajula@oulu.fi; Address: Research Unit of Nursing Science and Health Management, University of Oulu, Oulu, Finland.
}

Published by Sciedu Press 
them understand hereditary disease, disease transmission and the options for preventing the disease. ${ }^{[8-10]}$ Several studies have found that counselees with identified risks of hereditary cancer syndromes were generally satisfied with the GC they received, in countries including Norway and Canada. ${ }^{[1,12]}$ Previous studies have also found that counselees mainly want important medical information and advice in GC sessions, and information on the GC procedure. ${ }^{[13]}$ According to a Norwegian study, counselees consider genetic counselors' medical knowledge to be an important factor for addressing post GC-related worries. ${ }^{11]}$ Male BRCA1/2 mutation carriers have also reported high satisfaction levels with GC in Canada ${ }^{[14]}$ and good-quality GC in Finland. ${ }^{[15]}$ Participants deemed the medical information about cancer risks they received to be sufficient in the Finnish study ${ }^{[15]}$ and adequate in the Canadian study. ${ }^{[14]}$ However, participants in the Finnish study reported a lack of psychosocial support in GG. ${ }^{[15]}$ Moreover, the possibilities that positive genetic test results could cause fear of cancer developing, ${ }^{[16]}$ and that male BRCA1/2 mutation carriers may have various emotional reactions, ${ }^{[14]}$ should be noted. It is especially important to recognize male carriers who have strong emotional reactions to positive genetic test results, and provide adequate support for them. ${ }^{[17]}$ Counselors' ability to meet the counselees' psychological needs in a satisfying manner is also an important factor for satisfaction with GC of counselees with hereditary cancer syndromes. ${ }^{[18]}$ Accordingly, genetic counselors have recognized a need for better training to prepare them for encountering counselees' grief and loss, then implementing appropriate GC. ${ }^{[18-20]}$

In summary, a number of studies have explored counselees' satisfactions with GC and examined contents of GC session, in terms as sufficiency of medical information for counselees and factors the counselees consider to be important for them. Several studies have focused on hereditary cancer syndromes and female BRCA1/2 mutation carriers. However, few studies have focused on GC for male BRCA1/2 mutation carriers. Although these males have lower risks for developing cancer than female counterparts, genetic health-care professionals should be conscious of possible effects of male carriers' emotional reactions. It is important to identify elements of GC that male BRCA1/2 mutation carriers require and, with the growth of genetic testing, there is a need for DCGs to assess their GC practices. Hence, this study was designed to elicit experiences of male BRCA1/2 mutation carriers, specifically Finnish male carriers, and their suggestions for improving $\mathrm{GC}$, thereby providing the first broad description of experience of GC from the perspective of male BRCA1/2 mutation carriers.

Two specific research questions were addressed: 1) What 120 kind of experiences did the participants have the GC? 2) What kind of needs for improving GC they did perceive?

It should be noted that in Finland, recommendations for GC are made at the Departments of Clinical Genetics (DCGs) at university hospitals and GCs are conducted by clinical geneticists or trained genetic nurses. So, in this study the term 'counselor' refers to clinical geneticists or genetic nurses.

\section{Methods}

\subsection{Participants}

The participants were Finnish male BRCA1/2 mutation carriers $(n=31)$. Twenty-seven of them had participated in a previous survey study ${ }^{[15]}$ and confirmed their willingness to continue as participants in the present study. These men were recruited from five DCGs around Finland, and provided written consent to participate in this interview study. Another three men from one of the DCGs were recruited by sending out an invitation letters with a consent form, to include men who had received BRCA1/2 genetic test results no more than 1 year before the interviews, to capture recent experiences of GC. Additionally, a man who had participated in a preinterview was included in the sample because the interview themes had not changed subsequently. The final sample size was therefore 31 .

\subsection{Ethical aspects}

The study was approved by the Research Ethics Committee of the Northern Ostrobothnia Hospital District (60/2013 $133 \S, 201586 \S)$. All participants signed an informed consent form, and had an opportunity to discuss any sensitive issues raised during the interview with researcher after the interview. Participation was voluntary and anonymity was protected throughout the entire study process.

\subsection{Interview assessment}

The interviews covered demographic information and themes based on the quality of GC according to Finnish male BRCA1/2 mutation carriers $^{[15]}$ and previous studies ${ }^{[11,14]}$ on the experiences of GC for hereditary cancer syndromes. The themes were experiences of GC and the development of GC. The data were collected through interactive communication about the themes with defining questions such as: "How would you describe the GC situation and the GC session as a whole?", "How would you describe the information that you received during the GC session?", "What kind of psychosocial support would you want if any?" and "Does GC in your opinion require improvement and, if so, how would you improve it?". The themes and technique of the interviews were pretested with two male BRCA1/2 mutation carriers, who had been identified as BRCA1/2 mutation carriers for

ISSN 1925-4040 E-ISSN 1925-4059 
more than 7 years and had not participated in a previous study. After the pretesting the order of themes was changed, but no other aspect of the interviews.

\subsection{Data collection}

All interviews were carried out face-to-face in a private setting between September 2015 and June 2016. The interviews were approximately $80 \mathrm{~min}$ long (range 33-149 $\mathrm{min}$ ) and carried out in the participants' own homes (52\%), regional hospitals $(22 \%)$, health centers $(10 \%)$ or other places $(16 \%)$ such as a library. Spouse participated in interviews with two of the men (in accordance with men's wishes), but their comments were not included in the data analysis.

The interviews were taped and coded. The participants willingly discussed and shared their experiences about the issues in-depth and had open mind toward the interview. Thus, the content of the interviews was rich and many-sided. The data were saturated, i.e., no new information arose in the later interviews. The data were transcribed partly by the researcher and partly by a text processor from the hospital, with permission from the study participants. The text processor received only the coded and taped material. The resulted in 746 pages of written data (with single-line spacing and $6 \mathrm{~cm} / 2.5 \mathrm{~cm}$ margins); a large volume of data for a qualitative study.

\subsection{Data analysis}

The data were analyzed using inductive content analysis. ${ }^{[21]}$ Briefly, the researcher (O.K.) read the transcripts several times and made notes to reach a deeper understanding. The chosen analysis unit was a complete thought expressed in one or several sentences. After selecting the unit, the data were read in relation to the questions mentioned in section 1 , and the answers were written as open codes. The content of the open codes was compared by looking for similarities and differences between them. Similar open codes were grouped together into subcategories that were then grouped into categories. Data analysis was continued until all the categories were grouped into main categories. All the categories were given names according to the content they described. The analysis was entirely qualitative, i.e., no numerical results are presented. The questions were addressed by coping and categorizing participants' comments, and authentic quotes are used to indicate connections between categories and raw data.

\section{Results}

\subsection{Characteristics of participants}

The mean age of the participants was 59 (range 33-82) years and the average time since receiving a BRCA1/2 test result was over 4 years prior to the interviews (range 5-114 months). Of the participants, 55\% carried BRCA2 and 26\% carried BRCA1 mutations, while $19 \%$ did not remember which gene was mutated. Twenty-eight of the participants were living in a relationship and 26 participants had children. Seven participants $(23 \%)$ had been diagnosed with cancer: breast $(n=2)$, prostate $(n=2)$, colon $(n=3)$ and skin cancer $(n=$ $1)$ and 3 with another cancer, such as pancreatic cancer. Two had more than one type of cancer.

\subsection{The experiences of genetic counseling}

Reported experiences of GC (outlined below) were assigned to two main categories: the operational conditions of the DCG and the counselor's readiness and attitude. Both included several subcategories (see Figure 1).

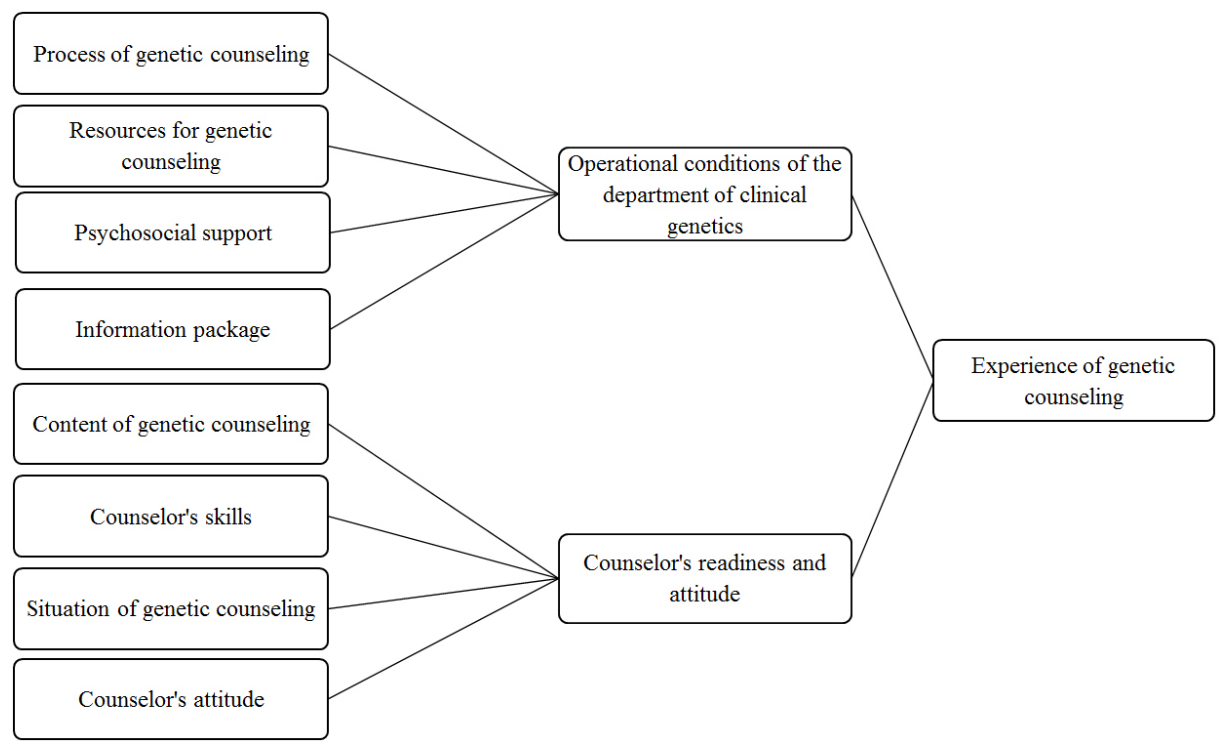

Figure 1. Experiences of genetic counseling 


\subsubsection{Main category: The operational conditions of the Department of Clinical Genetics}

The participants reported a mixture of both positive and negative experiences of the operational conditions of the DCG, in terms of process of the $\mathrm{GC}, \mathrm{GC}$ resources, psychological support and provision of written material. The participants had positive views of the GC overall, including their personal GC and possibility of receiving genetic test results at the DCG. The participants said it was simple to seek GC, and find out who to contact if there were additional questions, which was important. However, negative experiences were also noted, including the GC process taking too long, difficulties in seeking GC, and a lack of personal GC and post-test counseling.

It was found also that health-care professionals did not inform the subjects the importance of GC and genetic tests to help with the decision-making for receiving GC.

"I was not convinced that this will give me much benefit. I wondered if they do it just because some skilled researcher will find out that there is another new hereditary disease or some such reason. I didn't know if I would also get something from it."

The participants also said that GC was conducted in a space that was peaceful, but also oppressive and unfamiliar. Only one participant had been offered psychosocial support if needed. Moreover, they noted a lack of peer and organized psychosocial support; the DCGs did not arrange psychosocial support, or have a program for charting psychosocial requirements. Written information packages had helped participants prepare for pre-test counseling. However, participants complained about a lack of pre-information about the BRCA1/2 mutation, which made preparation for the GC and the GC process difficult as it was a new and strange issue. Information concerning the issue was instead obtained from websites and the issue was discussed with relatives.

"It would have been nice if I had got some information before GC, such as, what this means, this mutation or anything else, what it is supposed to mean in practice. In that case, I would have remembered at least the mutation's name and it would also have been nice to get an overall of what would happen in the GC and what would be possible to do in this phase. As it was, I tried to remember at home what it was and my mom gave her document to me, so I could find more information from Google about what it was supposed to mean."

\subsubsection{Main category: The counselor's readiness and atti- tude}

Participants' reported experiences of counselors' readiness were divided into experiences of the GC and situation, the counselors' skills in implementing GC and their attitudes. They had positive views of the GC content if they had received from their counselor important, useful and sufficient information, i.e., information about heredity, risks and prevention of cancer for themselves, their female relatives and surveillance practices. Such information prompted the participants to arrange examinations in time to be diagnosed with cancer at an early stage, and helped them prepare for the genetic test results.

"Well, it was very pertinent, and facts and possibilities etc. were discussed. There was nothing like painting everything black, it was kind of good pre-information about the issue."

However, participants said they received enough basic information and assurance that there was nothing alarming about the situation. There was also a dearth of important information. Participants reported that they had received barely any information or only information in printouts from their counselor. Participants would have liked more details during the GC, e.g., facts about implications of positive BRCA1/2 mutation results for their health and life in the future, and how to proceed after identification as a carrier. A lack of instruction and guidance for breast self-examination was also reported.

"Well, one thing was that, like, what was meant by the self-examination of breasts, which was not explained in the GC session, they didn't say anything about what that means, about what you should be looking for, and where you should look for it. I had no knowledge of that before, and afterwards I found breast cancer searching instructions for women from a web magazine."

In contrast to participants receiving insufficient information, participants said also they had too much and too detailed information from their counselor, indicating that participants had little possibility to influence the level of information they received.

"I just wanted to know the possibility of getting a cancer diagnosis and how many years I had left, just that, I didn't know the whole rigmarole."

"There was perhaps a bit too much, and in that phase I didn't want so much information and 
not about mortality percentages and such like. I just thought that this doesn't look very good."

Participants' experiences of counselors' communication skills were also mixed. Participants reported that their counselors had a professional and purposeful manner, and gave information objective and clearly, using understandable language during the GC. Genetic test results had been given in a considerate and decorous manner, and the counselors provided useful facts such as the lifetime risk of cancer, and gave examples of studies about men with BRCA1/2 mutations.

Counselors seemed to recognize the importance of interactive communication with the participants, and taking the men's individuality into account. The counselors addressed issues that were new to the participants in a reflective manner, and although the communication was about disease and death, it was not a negative experience for the participants. However, participants had also neutral experiences of GC, regarding it as just a discussion that did not raise any emotions, and they had also negative perceptions of counselors' skills:

"The GC session did not go according to the rulebook."

"There was nothing, they just told me the test result and asked if I had any questions, nothing else."

Participants' wishes to find out their test results and make informed decisions were underestimated by the counselors. Moreover, counselors used incomprehensible language and provided no opportunities for participants to communicate with them.

"It was still harder when I went to get the test results. I even said to the doctor, that does she think that I have so bad memory, for God's sake I shouldn't have to say ten times that they can give me the results. Then we discussed other things and then she asked again, so when she had already asked probably five to six times, I asked what she playing at, I wanted to know the results. This kind of hesitation made me angry."

Other positive experiences of GC included counselors' management of the GC situation in a manner that created a human, comfortable and convivial atmosphere, with a sense that there was nothing to fear. The counselors had enough time to carry out GC without haste, and the GC was considerate and straightforward. GC was not thought to be as serious as contracting cancer by the participants with a cancer diagnosis.
"The action there was really considerate on the whole, a very pleasant situation, though the issue was quite serious, very pleasant, not fraught at all to my mind."

"Hereditary examination was nothing compared to getting the cancer. Well it was actually only the information, that confirmed that I had it, that it was now just fate."

However, there were also negative experiences of counselors' management of the GC situation, specifically that sometimes the $\mathrm{GC}$ was too short, restricted to receiving facts about being identified as a carrier of a BRCA1/2 mutation, or too long, sometimes even hours.

Similarly, the counselors' attitudes elicited both positive and negative responses. The counselor was found to be friendly, pleasant and treated the issues positively and scientifically. However, experiences of counselors adopting a dismissive attitude towards being a BRCA1/2 mutation carrier were also described. The counselor's attitude was not supposed to frighten the men during the $\mathrm{GC}$, but the participants felt also that their counselor was more worried about the issue than they were.

\subsection{Development of genetic counseling}

As described below, suggestions to improve GC were divided into four main categories, each with several subcategories (see Figure 2): before pre-test GC, pre- and post-test GC, after post-test $\mathrm{GC}$, and various situations in the life of a male BRCA1/2 mutation carrier.

\subsubsection{Main category: Before pre-test genetic counseling}

Suggestions to improve GC before pre-test sessions included the provision of information about the issues that might be discussed and the GC process, which would allow men to express willingness to discuss issues during the GC, prepare for the sessions, and help them to get as much as possible from the GC. Pre-test preparations could also allow counselors to become aware of counselees' possible problem areas and tailor GC meetings to meet counselees individual needs and situations.

"Well my opinion is that nowadays to healthcare problems should be charted in advance because then professionals can see what the problems are and they already have information when you come for counseling." 


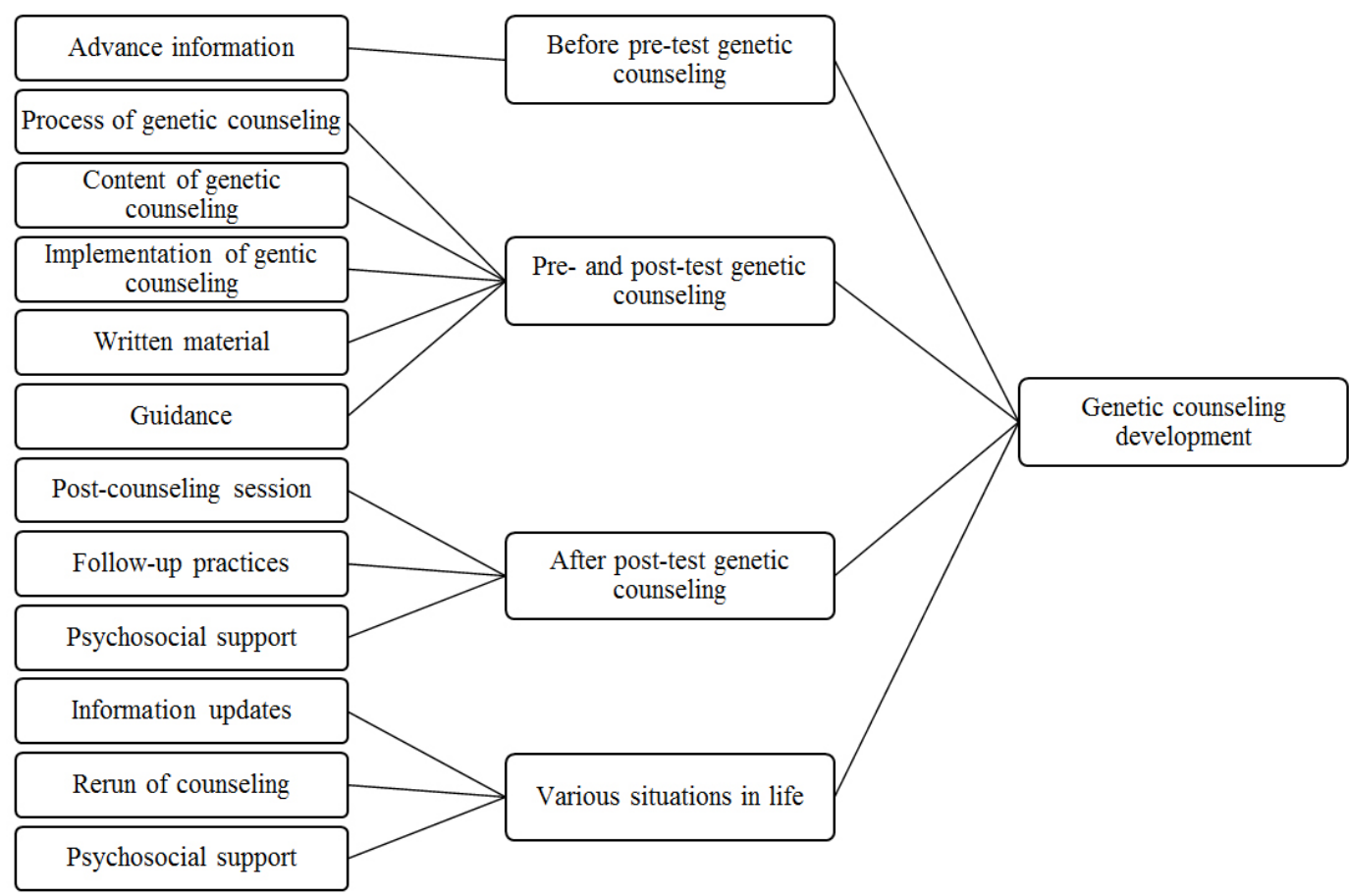

Figure 2. Genetic counseling development

3.3.2 Main category: Pre- and post-test genetic counseling

Further recommendations for improving the GC process included introducing possibilities to have a personal pre-test GC session, receiving genetic test results at the DCG, and taking individual's wishes into account in GC sessions. Participants also suggested that GC process could be shorter, and part of the treatment process if cancer had been diagnosed. Moreover, the content and sufficiency of information in GC sessions could be agreed, based on the individual's needs, and counselees should be treated with respect, in a human to human manner.

The participants thought that counselors should consider how to manage the sessions and tailor the information given at pre- and post-test GC sessions in accordance with the individual's way of learning. They also suggested that counselors should give information covering one issue at a time, and recapitulate it in a $\mathrm{GC}$ session.

"The counselors should ask during the GC about the counselees' mode of learning, and use it so that counselees can assimilate new knowledge quickly."

The participants also recommended the automatic provision of written material about issues such as BRCA1/2 mutations, the genetic test results and follow-up plans in the post-test $\mathrm{GC}$ session, due to the importance of managing identification as a BRCA1/2 mutation carrier, and providing information for spouses, children and other family members. A further advantage mentioned is that this would facilitate following surveillance recommendations. They also thought that malespecific advice and guidance should be provided during posttest GC sessions on carrying out breast self-examination, healthy eating and healthy lifestyles.

"I didn't know about all of that, we didn't speak how it influences. I mean, okay I know that snuff influences everything, but what kind of meaning everything has, generally speaking, rules and opportunities, all those sorts of things would be good to know. I guess not so many thing, just how to behave after this, or like healthy eating and that kind of thing."

\subsubsection{Main category: After post-test genetic counseling}

The participants expressed beliefs that post-test counseling could be improved by automatically organizing a second counseling session, tailored to the individual's needs and willingness, either at a DCG or over the telephone, ideally a week to 6 months after being identified as a BRCA1/2 mutation carrier. They also mentioned that regular, comprehensive follow-ups could be arranged automatically by specialists.

"I hope that a follow-ups should be arranged at a special health-care center because they really know about this there." 
Further proposals included development of more psychosocial support for male BRCA1/2 mutation carriers, including monitoring their needs for such support and creating tailored programs. The participants felt there should be opportunities for psychological and occupational therapy, if necessary and a male-specific peer support group.

\subsubsection{Main category: Various situations in life}

If important new information for male BRCA $1 / 2$ mutation carriers emerges, the participants felt they should be informed automatically by letter or a restricted-access website developed for that purpose. Such a website could also provide information about various situations and answers for specific questions relevant to BRCA1/2 mutation carries. They also thought it would be useful for DCGs to organize open public lectures about relevant issues when important new information appears, and further counselling sessions after life-changing events, e.g., telling children about the risk of inheriting a BRCA1/2 mutation, or a cancer diagnosis. Similarity, there were calls for opportunities to have psychosocial support after a cancer diagnosis and peer support for various life situations.

"I guess it comes around again when you are diagnosed with cancer, then it is like the same situation, but then when you are in that phase you don't know who'll have bad luck and who'll have better luck, so support will be important."

\section{Discussion}

Our study provides novel insights into male BRCA1/2 mutation carriers' perceptions of GC, including (to our knowledge) the broadest reports of their experiences of GC and the first counselees' descriptions of elements of male- specific GC.

The participants reported mixtures of both positive and negative experiences of the DCGs' operational conditions and the counselors' readiness and attitudes. The results indicate that DCGs should consider their operational conditions in terms of the ease for carriers, or potential carriers, to seek and obtain GC, the duration of GC sessions and the GC process. Shortening times between $\mathrm{GC}$ and the disclosure of genetic test results may be especially important, as this can be an emotionally stressful time for hereditary cancer counselees. ${ }^{[22]}$ It is also apparently important for DCGs to take account of counselees' suggestions about GC provisions, especially possibilities to provide GC because by telephone if they have to travel long distances for physical visits. Although GC and receiving genetic test results face-to-face were important for participants, there seemed to be a desire for this option, in accordance with previous findings that fe-

Published by Sciedu Press male and male counselees of a BRCA predictive test wanted the ability to decide how the test result was disclosed. ${ }^{[23]}$ Another study also found that breast cancer patients were satisfied with the type of GC they chose before genetic testing and would choose the same type again. ${ }^{[24]}$ Overall, these studies support indications in our study that the DCG service model was related to the experiences of the participants. However, contrary findings that the GC delivery model was not associated with satisfaction in GC in general for women with a BRCA1/2 mutation have been reported. ${ }^{[25]}$

Participants felt that they did not receive information about the importance of the GC from the health-care professionals, in accordance with previous findings that health-care professionals can play an important role in helping women with breast cancer decide whether or not to have GC. ${ }^{[26,27]}$ Our participants also mentioned that they received inadequate written material, in line with findings that most women with breast or ovarian cancer were inadequately prepared because of lack of pre-information. ${ }^{[28]}$ Moreover, they strongly believed that DCGs provided insufficient facilities for psychosocial support, like counselees with hereditary cancer in a previous study, which suggested that counselees should have opportunities to receive psychosocial support through the GC process $^{[22]}$ regardless of their educational background. Educational background is potentially relevant in this context as there are indications that counselors may propose psychological services to highly educated counselees more often than to others. ${ }^{[29]}$

The participants had diverse experiences of the counselors' readiness, although they generally concurred that the counselors had genetic knowledge. This is broadly consistent with findings that that training resource for cancer genetic counselors' should be improved to help them understand the contexts of the issues. ${ }^{[19]}$ Our participants also felt that should have had more opportunity to influence the amount and nature of the information they received. This is consistent with findings that counselees have individual needs for the information about hereditary cancer they receive through $\mathrm{GC}$, and the optimal content and quantity of information depend on counselees' life management and characteristic. ${ }^{[30]}$

The participants generally expressed satisfaction about their counselors' skills to provide GC in a professional manner and take account of their individuality, in accordance with previous recommendations that it is important for counselors to have high skills, and that good skills promote feelings of safety among counselees. ${ }^{[11]}$ However, our participants expressed negative perceptions of counselors' course of action and attitudes. Alarmingly, men felt that their decisionmaking was belittled because they had a BRCA1/2 mutation, 
and/or did not have a dialogue with the counselors, which disappointed them. This corroborates the importance of counselors responding to counselees' individual views and ensuring that they understand received information. ${ }^{[29,31]}$ Supervisors could play important roles in helping genetic counselors students to understand and develop psychosocial skills during their education. ${ }^{[32]}$ Thus, both our study and earlier findings indicate that may be valuable for DCGs to have experienced genetic professionals to tutor novice counselors, especially in countries that do not offer special education for genetic counselors.

The participants had views about developing GC that were consistent with their experiences of it, emphasizing the value of receiving advance information about issues in order to plan personal GC sessions before pre-test GC, and counselors taking into account the individual's methods of learning and needs during pre- and post-test counseling.

The importance of valuing individuals' views regarding these aspects of GC has been previously noted. ${ }^{[23]}$ Our results extend this observation by indicating that motivational, substantive and illustrative GC (with shared, appropriate written material to be discussed during GG sessions) could not be provided entirely over the telephone. Counselors also reportedly feel that telephone-mediated GC may be insufficient, due to risks of misinterpretation of information and inadequate communication. ${ }^{[33]}$ Moreover, our participants highlighted the importance of advice about breast self-examination techniques and guidance about a healthy lifestyle, in line with a previous review of counseling for male BRCA1/2 mutation carriers. ${ }^{[7]}$ Furthermore, our results highlight perceived needs for a second GC session and regular follow-ups, automatically arranged after post-test counseling. The participants also articulated a need for charted psychosocial support, and a male-specific support group for male carriers, in line with previous reports. ${ }^{[14,22]}$ A support group has clear potential benefits as it offers participants opportunities to discuss and share experiences with others, and to receive new information from health-care professionals. ${ }^{[14,34]}$ Proposals for a protocol for BRCA1/2 GC testing and GC tailored to counselees needs, based on studies of the psychological impact of BRCA $1 / 2$ testing, ${ }^{[35]}$ and also consistent with our findings.

Finally, our findings highlight the needs for information updates and opportunities for psychosocial support when life situations change for male BRCA1/2 mutation carriers. A restricted-access website could play important roles in this respect, e.g., for sharing new information, enabling participants to check the issues that were not discussed in GC and providing a social media support forum. This too is consistent with views of participants in another study, that creating a user-friendly website with informative and understandable language, and blogs for peer support, would be useful. ${ }^{[22]}$

\subsection{Limitations}

Several limitations and strengths affect the trustworthiness of this study. The strengths include the size of the group of male BRCA1/2 mutation carriers that participated, and both the richness and saturation of the acquired data. Moreover, all the participants were identified as BRCA1/2 mutation carriers and willingly shared their experiences during the interviews, which were carried out in peaceful environments chosen by the participants and conducted by one researcher (O.K.), who has longitudinal experiences of GC for patients with hereditary cancer syndromes. In addition, pre-interviews were performed to validate the data collection method, interviewees' comments were transcribed verbatim. Confirmability was ensured by carrying out the data gathering process in an agreed way. The data were described in as much detail as possible and authentic quotes were taken from the interviews. One researcher (O.K.) conducted the data analysis, but the analysis and formulation of the categories and their names were discussed with another researcher (H.K.). Moreover, all the researchers discussed and commented on the entire data analysis process.

A limitation is that some of the participants had received their BRCA1/2 test results a long time ago before the interviews, which may affect their experiences and how accurately they remembered them. However, some participants had received their test results less than a year before their interviews and their experiences were very similar to those of participants who had been diagnosed earlier. Another limitation, which is typical for qualitative studies, is that the results cannot be readily generalized. However, they can be transferred and used to develop GC for other hereditary cancer syndromes. In Finland, there is no specific, official curriculum for graduate programs for genetic counselors. Genetic counseling sessions are provided by clinical geneticists or additionally educated genetic nurses. We are confident that the results of our study can be applied in countries that lack specifically trained genetic counselors.

The present study describes the experiences of male BRCA1/2 mutation carriers, which may restrict direct application of the results to $\mathrm{GC}$ for other conditions. Wider applicability will require examination of the GC experiences of female BRCA1/2 mutation carriers and carriers of other hereditary cancer-associated mutations.

\subsection{Clinical implications}

Our findings indicate that DCGs should develop GC practices for male BRCA1/2 mutation carriers in accordance with 
their needs, as follows: 1) carriers should receive advance information before GC to help prepare and chart individual needs for GC; 2) GC should be tailored to counselees' wishes and individual needs in terms of content and individual counselees' methods of learning; 3) after post-test GC, a second counseling session should be organized, additional GC should be provided if needed after changes in life situation, and 4) automatic, regular follow-ups for male carriers; 5) psychosocial support should be arranged to meet individuals' psychosocial needs and peer support after BRCA1/2 test disclosure and after any changes in life situations; 6) written material should be provided, and 7) a restricted-access website for providing information. Our study also indicates that DCGs should organize further training on to improve counseling skills e.g., communication skills with counselees, and the readiness of counselors who carry out GG. Finally, we recommend that counselors should understand the emotions of BRCA1/2 mutation carriers, and that DCG the use experienced professionals as mentors to improve for counselors' skills.

A tentative model of GC could be developed using the results of our study, but further research is needed to develop a wider model of GC for carriers of (and patients diagnosed with) hereditary cancer syndromes. This research should focus on female BRCA1/2 mutation carriers and markers of other hereditary cancer syndromes to provide a more refined model of $\mathrm{GC}$ with broader nuances. It would also be interesting to study experiences regarding readiness and training needs from the counselors' perspective.

\section{Conclusions}

In summary, our study shows that Finnish male BRCA1/2 mutation carriers generally had positive experiences of some aspects of GC. However, they also noted many negative experiences and raised issues that could be used to improve GC. We suggest some elements for tailored GC for male BRCA1/2 mutation carriers, notably the importance of attention to the counselees' individual needs for GC and psychosocial support. Our study also shows that the counselors' readiness for implementing GC should be considered, and highlights the need to provide additional training for counselors.

\section{ACKNOWLEDGEMENTS}

The authors express gratitude to all male carriers who participated in this study. Clinical geneticists, genetic nurses and assistants at the Departments of Clinical Genetics in Finland are thanked for their help with data collection. We also thank the text processor for assistance with data transcription. The Cancer Society of Finland, Ella and Georg Ehrnrooth Foundation, Finnish Foundation of Nursing Education, Thelma Mäkikyrö Foundation and Competitive State Research Funding are thanked for supporting the study with grants.

\section{Conflicts OF InTEREST Disclosure}

There are no conflicts of interest for the authors of this article.

\section{REFERENCES}

[1] Miki Y, Swensen J, Shattuck-Eidens D, et al. A strong candidate for the breast and ovarian cancer susceptibility gene BRCA1. Science. 1994; 266(5182): 66-71. PMid:7545954 https://doi .org/10.1 126 /science. 7545954

[2] Wooster R, Bignell G, Lancaster J, et al. Identification of the breast cancer susceptibility gene BRCA2. Nature. 1995; 378(6559): 789792. PMid:8524414 https://doi .org/10.1038/378789a0

[3] Leongamornlert D, Mahmud N, Tymrakiewicz M, et al. Germline BRCA1 mutations increase prostate cancer risk. Br J Cancer. 2012; 106(10): 1697-1701. PMid:22516946 https ://doi .org/10.103 $8 /$ bjc. 2012.146

[4] Tai YC, Domchek S, Parmigiani G, et al. Breast cancer risk among male BRCA1 and BRCA2 mutation carriers. J Natl Cancer Inst. 2007; 99(23): 1811-1814. PMid:18042939

[5] Petrucelli N, Daly MB, Pal T. BRCA1- and BRCA2-associated hereditary breast and ovarian cancer. In: Pagon RA, Adam MP, Ardinger $\mathrm{HH}$, et al, eds. GeneReviews(R). Seattle (WA): University of Washington, Seattle. NCBI Bookshelf, National Institutes of Health. Available from: https://www.ncbi.nlm.nih.gov/books/NBK1247

Published by Sciedu Press
/. Published 1998. Updated December 15, 2016. Accessed February 20, 2017.

[6] Evans DG, Susnerwala I, Dawson J, et al. Risk of breast cancer in male BRCA2 carriers. J Med Genet. 2010; 47(10): 710-711. PMid:20587410 https://doi.org/10.1136/jmg. 2009.07517 6

[7] Mohamad HB, Apffelstaedt JP. Counseling for male BRCA mutation carriers: A review. Breast. 2008; 17(5): 441-450. PMid:18657973 https://doi.org/10.1016/j.breast.2008.05.001

[8] Trepanier A, Ahrens M, McKinnon W, et al. Genetic cancer risk assessment and counseling: Recommendations of the national society of genetic counselors. J Genet Couns. 2004; 13(2): 83-114. PMid:15604628 https://doi.org/10.1023/B: JOGC. 0000018 821.48330 .77

[9] National Society of Genetic Counselors' Definition Task Force, Resta $\mathrm{R}$, Biesecker BB, et al. A new definition of genetic counseling: National society of genetic counselors' task force report. J Genet Couns. 2006; 15(2): 77-83. https://doi.org/10.1007/s10897-005 $-9014-3$

[10] EuroGentest. Recommendations for genetic counselling related to genetic testing. Available from: http://www. eurogentest.org/ 
index . php?id=674 Published 2008. Accessed February 20, 2017.

[11] Bjorvatn C, Eide GE, Hanestad BR, et al. Risk perception, worry and satisfaction related to genetic counseling for hereditary cancer. J Genet Couns. 2007; 16(2): 211-222. PMid:17279329 https : //doi.org/10.1007/s10897-006-9061-4

[12] Metcalfe KA, Poll A, Llacuachaqui M, et al. Patient satisfaction and cancer-related distress among unselected Jewish women undergoing genetic testing for BRCA1 and BRCA2. Clin Genet. 2010; 78(5): 411-417. PMid:20653694 https://doi .org/10.1111/j . 1399-0004.2010.01499.x

[13] Pieterse A, van Dulmen S, Ausems M, et al. QUOTE-gene(ca): Development of a counselee-centered instrument to measure needs and preferences in genetic counseling for hereditary cancer. Psychooncology. 2005; 14(5): 361-375. PMid:15386761 https ://doi .org/10 $.1002 /$ pon. 853

[14] Liede A, Metcalfe K, Hanna D, et al. Evaluation of the needs of male carriers of mutations in BRCA1 or BRCA2 who have undergone genetic counseling. Am J Hum Genet. 2000; 67(6): 1494-1504. PMid:11063672 https ://doi.org/10.1086/316907

[15] Kajula O, Kaariainen M, Moilanen JS, et al. The quality of genetic counseling and connected factors as evaluated by male BRCA1/2 mutation carriers in Finland. J Genet Couns. 2016; 25(3): 413-421. PMid:26416184 https://doi.org/10.1007/s10897-015-988 $5-\mathrm{x}$

[16] Stromsvik N, Raheim M, Gjengedal E. Cancer worry among Norwegian male BRCA1/2 mutation carriers. Fam Cancer. 2011; 10(3): $597-$ 603. PMid:21603983 https://doi.org/10.1007/s10689-011 $-9456-8$

[17] Stromsvik N, Raheim M, Oyen N, et al. Stigmatization and male identity: Norwegian males' experience after identification as BRCA1/2 mutation carriers. J Genet Couns. 2010; 19(4): 360-370. PMid:20306122 https://doi.org/10.1007/s10897-010-929 3-1

[18] Geller G, Rushton CH, Francomano C, et al. Genetics professionals' experiences with grief and loss: Implications for support and training. Clin Genet. 2010; 77(5): 421-429. PMid:20447149 https://doi.org/10.1111/j.1399-0004.2010.01409.x

[19] Lane M, Ngueng Feze I, Joly Y. Genetics and personal insurance: The perspectives of Canadian cancer genetic counselors. J Genet Couns. 2015; 24(6): 1022-1036. PMid:25925606 https : //doi.org/10.1007/s10897-015-9841-9

[20] Shugar A. Teaching genetic counseling skills: Incorporating a genetic counseling adaptation continuum model to address psychosocial complexity. J Genet Couns. 2016. https : //doi .org/10.1007/s108 97-016-0042-y

[21] Elo S, Kyngas H. The qualitative content analysis process. J Adv Nurs. 2008; 62(1): 107-115. PMid:18352969 https : //doi.org/ 10.1111/j.1365-2648.2007.04569.x

[22] Mendes AF, Santos TA, Sousa L. Experiencing genetic counselling for hereditary cancers: The client's perspective. Eur J Cancer Care (Engl). 2011; 20(2): 204-211. PMid:20597958 https : //doi .org/ 10.1111/j.1365-2354.2010.01201.x

[23] O'Shea R, Meany M, Carroll C, et al. Predictive genetic testing and alternatives to face to face results disclosure: A retrospective review of patients preference for alternative modes of BRCA 1 and 2 results disclosure in the republic of ireland. J Genet Couns. 2016; 25(3): 422 431. PMid:26407988 https://doi.org/10.1007/s10897-015 $-9887-8$

[24] Sie AS, Spruijt L, van Zelst-Stams WA, et al. High satisfaction and low distress in breast cancer patients one year after BRCA-mutation testing without prior face-to-face genetic counseling. J Genet Couns. 2016; 25(3): 504-514. PMid:26531312 https://doi.org/10.1 007/s10897-015-9899-4

[25] Peshkin BN, Kelly S, Nusbaum RH, et al. Patient perceptions of telephone vs. in-person BRCA1/BRCA2 genetic counseling. J Genet Couns. 2016; 25(3): 472-482. PMid:26455498 https ://doi.org/ 10.1007/s10897-015-9897-6

[26] Anderson B, McLosky J, Wasilevich E, et al. Barriers and facilitators for utilization of genetic counseling and risk assessment services in young female breast cancer survivors. J Cancer Epidemiol. 2012; 298745. https://doi.org/10.1155/2012/298745

[27] Kne A, Zierhut H, Baldinger S, et al. Why is cancer genetic counseling underutilized by women identified as at risk for hereditary breast cancer? patient perceptions of barriers following a referral letter. J Genet Couns. 2016. https : //doi .org/10.1007/s10897 -016-0040-0

[28] Hallowell N, Murton F, Statham H, et al. Women's need for information before attending genetic counselling for familial breast or ovarian cancer: A questionnaire, interview, and observational study. BMJ. 1997; 314(7076): 281-283. PMid:9022494

[29] Maheu C, Bouhnik AD, Nogues C, et al. Which factors predict proposal and uptake of psychological counselling after BRCA1/2 test result disclosure? Psychooncology. 2014; 23(4): 420-427. PMid:24127257 https ://doi.org/10.1002/pon. 3435

[30] Hayat Roshanai A, Lampic C, Ingvoldstad C, et al. What information do cancer genetic counselees prioritize? J Genet Couns. 2012; 21(4): 510-526. PMid:21993709 https ://doi.org/10.1007/s1 0897-011-9409-2

[31] Vos J, Oosterwijk JC, Gomez-Garcia E, et al. Perceiving cancer-risks and heredity-likelihood in genetic counseling: How counselees recall and interpret BRCA 1/2-test results. Clin Genet. 2011; 79(3): 207 218. PMid:21114486 https ://doi .org/10.1111/j.1399-000 4.2010.01581.x

[32] Borders LD, Eubanks S, Callanan N. Supervision of psychosocial skills in genetic counseling. J Genet Couns. 2006; 15(4): 211-223. PMid:16865562 https ://doi.org/10.1007/s10897-006-902 4-9

[33] Bradbury AR, Patrick-Miller L, Fetzer D, et al. Genetic counselor opinions of, and experiences with telephone communication of BRCA1/2 test results. Clin Genet. 2011; 79(2): 125-131. PMid:21039431 https://doi.org/10.1111/j.1399-0004.20 10.01540.x

[34] Myklebust M, Gjengedal E, Stromsvik N. Experience of norwegian female BRCA1 and BRCA2 mutation carrying participants in educational support groups: A qualitative study. J Genet Couns. 2016; 25(6): 1198-1206. PMid:27091466 https ://doi.org/10.1007/ s10897-016-9954-9

[35] Van Oostrom I, Tibben A. A counselling model for BRCA1/2 genetic susceptibility testing. Hered Cancer Clin Pract. 2004; 2(1): 1923. PMid:20233480 https://doi .org/10.1186/1897-4287-2 $-1-19$ 